\title{
SER QOM: LOS DESAFÍOS DE LA REALIZACIÓN AUDIOVISUAL INTERCULTURAL
}

José Cuevas1: Universidad Carlos III de Madrid. España jcuevas@hum.uc3m.es

Amelia Álvarez: Universidad Carlos III de Madrid. España aarodrig@hum.uc3m.es

Anto J. Benítez: Universidad Carlos III de Madrid. España abenitez@hum.uc3m.es

\section{RESUMEN}

Se presenta en este trabajo el proceso de elaboración de un documental sobre las prácticas culturales de un grupo de miembros de la etnia Qom procedentes de la región argentina del Chaco (región de Pampa del Indio, Villa Río Bermejito y Resistencia) y de la comunidad de Derqui en Buenos Aires (estos últimos inmigrados. Este trabajo se basa en los resultados del proyecto llevado a cabo durante el año 2010 financiado por la Agencia Española de Cooperación Internacional para el Desarrollo (proyecto PCI A/025747/09) y por la Fundación Infancia yAprendizaje (programa Futuros Humanos FH01001). El documental fue realizado a partir de un material videograbado por los propios miembros qompi, dirigido al estudio de los contextos de actividad de sus comunidades con un doble objetivo: diseñar materiales educativos para las escuelas de educación bilingüe castellano-qom'lek basados en los usos de la lengua en contextos cotidianos y realizar un diagnóstico de la pervivencia y estado de la cultura qom en la actualidad. Primero se realizó un seminario-taller con miembros de las comunidades citadas, entre los cuales había tanto educadores que estaban participando en la elaboración de materiales educativos, como líderes de las comunidades, y se llevó a cabo una primera aproximación a los elementos básicos de su identidad. Posteriormente, se impartió un breve curso sobre técnicas de grabación con unas sencillas cámaras proporcionadas por el proyecto y se estableció un plan de grabaciones por temas, lugares y personas.

\footnotetext{
${ }^{1}$ Autor correspondiente

José Cuevas1: Universidad Carlos III de Madrid. España

Correo: jcuevas@hum.uc3m.es
} 
PALABRAS CLAVE: Realización compartida - Antropología visual - Autoría audiovisual - Cultura Qom - Etnias Latinoamericanas

\title{
TO BE QOM: CHALLENGES TO INTERCULTURAL AUDIOVISUAL PRODUCTION
}

\begin{abstract}
This article describes the process of producing a documentary of cultural practices by members of the Qom ethnic group in Argentina. The participants were the inhabitants of Pampa del Indio, Villa Rio Bermejito and Resistencia, located in the northern Argentinian region of $\mathrm{El}$ Chaco. Also included was the community of Derqui on the outskirts of Buenos Aires, composed of Qoms who had migrated from the region of El Chaco. The documentary was produced using video material recorded by members of the Qom community for the purpose of documenting their social and cultural life. The project had a double objective: a) to develop educational materials based on daily language practices to be used as part of their bilingual school program (Castellano- qom'lek), and b) to facilitate diagnosis of the current situation and survival of Qom culture. In the first phase a workshop and seminar were held with Qom teachers who had had previous experience in developing this type of educational material and with community leaders in order to define the basic elements of Qom identity. In the second phase, a basic course on camera handling and recording was given to various Qom members with domestic cameras provided by the project. Finally, priorities were assigned regarding subjects, places, routines, and so on.
\end{abstract}

KEY WORDS: Collaborative Film-Making - Visual anthropology - Audiovisual authorship - Qom culture - Latin American Ethnics

\section{INTRODUCCIÓN}

La llegada de los equipos portátiles de vídeo y audio de carácter doméstico al mercado internacional, con posibilidad de registros automatizados, está facilitando la participación de grandes capas de la población en la realización de obras documentales, a pesar de contar con conocimientos muy básicos de las técnicas de grabación audiovisuales.

Desde hace una veintena de años son cada vez más numerosas las producciones fotográficas y cinematográficas de carácter documental y antropológico que defienden que sean los propios sujetos protagonistas de este tipo de obras los que generen su propio material audiovisual, dando una visión desde dentro del entorno social y natural al que pertenecen. Esta nueva forma de producción ha crecido exponencialmente a partir de la década de los noventa del pasado siglo gracias a las 
innovaciones tecnológicas acaecidas en el sector de la imagen digital, especialmente por la llegada de los equipos de grabación AV portátiles, de fácil manejo por las múltiples formas de automatismo que ofrecen a los usuarios no profesionales.

Entender la creación audiovisual de este modo tiene sus antecedentes más directos en el ámbito de la producción de documentales de las escuelas conocidas como Cinema Verité y Direct Cinema, surgidas en la década de los cincuenta del pasado siglo coincidiendo con la llegada entonces de las cámaras cinematográficas de 16 mm y los magnetófonos portátiles.

Al mismo tiempo, esta filosofía de trabajo se vio reforzada por la aparición en la década de los sesenta de los primeros audiovisuales participativos, promovidos por la Antropología Visual, a partir de las teorías de B. Malinowski defensoras de la visión desde el otro en los estudios etnográficos, y conscientes de la influencia recíproca entre investigador e informante. No obstante, debemos reconocer que el origen de este tipo de planteamientos en el audiovisual se remonta a los inicios del género documental, con la figura de R. J. Flaherty y su Nanook, el esquimal (Flaherty, 1922) si tenemos en cuenta los visionados de imágenes que hizo este autor conjuntamente con sus protagonistas previos al montaje definitivo de la película.

Esta senda se ha visto culminada en la actualidad con experiencias cinematográficas que defienden el traslado total de la responsabilidad autorial al sujeto filmado, tanto en las tareas de grabación como de montaje e incluso de distribución (Cine sin autor, 2010, a y b). Aunque existen ejemplos recientes de producción de este tipo dentro del cine comercial (Briski \& Kauffman, 2007), la antropología visual ha sido tal vez la disciplina más prolífica en este tipo de obras "interdisciplinarias, democráticas y colaborativas", encaminadas a hacer un cine no destinado al ocio sino a la transformación de la realidad, a mostrar realidades ocultas y recuperar la historia propia de los protagonistas y sus bienes (Camas, Martínez, Muñoz \& Ortiz, 2004).

Entre los numerosos proyectos afines a nuestra metodología de trabajo cabe destacar los de Turner (1990) con el pueblo Kapayo, Wang, Burris y Yue Ping (Kapayo, Wang, Burris \& Yue Ping 1996) sobre realización de fotonovelas con campesinas chinas, el de Barnes, Taylor-Brown y Wiener (Barnes, Taylor-Brown \& Wiener 1997) con grabaciones realizadas por madres con sida, y de forma especial aquellas realizadas en el ámbito de América Latina, y más particularmente con la comunidad qom, donde cabe destacar Qa Loq Laj Iyaaj, coordinado por Carlos y Flores (2005) con cineastas pertenecientes a las comunidades maya-q'eqchi'de Guatemala, el proyecto Vídeo Nas Aldeias, de Vincent Carelli (Vincent Carelli, 2011), vigente desde 1987 en diferentes zonas de Brasil; y, más particularmente, los que han contado con la participación directa de la comunidad Qom. 
Entre estos, debemos destacar el documental "Nam Qom. Una comunidad al margen", realizado en la ciudad de Rosario por Tarha Erena Sarmiento (Sarmiento, 2005); el proyecto de "antropología compartida" de Agustín Samprón (Samprón, 2001) con jóvenes qom residentes en La Plata, provincia de Buenos Aires; y el emprendido en 1986 por el LIAS de la Facultad de Ciencias Naturales y Museo, UNLP, Argentina (Tamagno \& Maidana, 2007) en el seno de las comunidades qom migradas a determinados suburbios de Buenos Aires, proyecto que quedó reflejado en el documental "Ntaunaq Nam Qom. Identidad y lucha por la tierra. Gente toba en la ciudad". Por nuestra parte, el objetivo ha sido construir una obra de comunicación audiovisual a partir de la visión interna que ha efectuado un grupo de la población qom sobre su propia cultura y del esfuerzo común de sus protagonistas y el equipo de realización para dar un sentido narrativo al grueso de las imágenes.

\section{DESARROLLO}

\section{1 “Ser Qom": el documental}

Como acabamos de comentar, el documental que se presenta, que hemos titulado "Ser Qom", nació de la idea de resumir en un documento breve el trabajo realizado por miembros de comunidades qom (con la asesoría de los investigadores del proyecto) en un proyecto piloto previo a la constitución de un banco de registros audiovisuales sobre su modo de vida y sus prácticas culturales. El objetivo último es contar con una "biblioteca-reservorio" de consulta tanto a los estudiosos de la cultura como, y sobre todo, a los propios miembros de las comunidades sociales y a las instituciones educativas en las que se están abordando proyectos de escolarización bi-culturales.

Partíamos pues de un material audiovisual obtenido por once miembros de la cultura qom (ayudados en algunos casos por familiares o amigos) mediante cámaras de video de uso doméstico desde abril a noviembre de 2010 en diferentes zonas de la provincia del Chaco y en la Comunidad Derqui, provincia de Buenos Aires.

En esta fase del proyecto se produjo una bifurcación en la autoría de la obra al darse una doble responsabilidad en la realización del mismo. Por un lado, se contaba con la grabación efectuada por los miembros de la comunidad; y, por otro, con el guión, montaje y sonorización, trabajos asumidos por los realizadores. La elección de una estructura narrativa que satisficiera las aspiraciones de la comunidad e investigadores, tratando de respetar en lo posible la forma y el sentir de las imágenes grabadas, fue tal vez el momento más decisivo en la producción de la obra.

Los dilemas más habituales de la antropología visual en torno a los métodos de investigación con poblaciones indígenas surgieron con vehemencia en esta fase del proyecto. ¿Hasta qué punto era posible una autoría compartida? ¿Se podía defender un modelo de producción audiovisual sobre una comunidad ajena a los de los propios realizadores sin que se produjeran interferencias y prejuicios entre una cultura y otra? En estas condiciones ¿podrían mantenerse propuestas narrativas compartidas? ;Tenían que ser los propios qompi los creadores totales de sus 
materiales y obras? ¿Podríamos considerar autores de una obra a los artífices de unas imágenes domésticas, carentes de unos requisitos técnicos mínimos de calidad exigibles?, o ¿hasta qué punto nos enfrentábamos a una clara e inequívoca apropiación de una obra, una cultura y un esfuerzo de unos habitantes a los que nos dirigíamos con un modelo de actuación pretendidamente de cooperación, o de antropología compartida, pero que bien pudiera subscribir el modo de actuar colonialista contra el que ellos mismos siguen combatiendo?

La descripción del proceso de elaboración del documental tal vez pueda ofrecer algunas pistas al respecto. Debemos reconocer que tras el primer visionado del material grabado en origen surgieron serias dudas sobre la viabilidad de construir una obra a partir del mismo. No apreciábamos suficiente número de planos compuestos correctamente desde un punto de vista fotográfico, cinematográfico, o de contenido relevante, como para articular una obra consistente.

Sin embargo, esta primera impresión fue poco a poco diluyéndose a medida que nos familiarizábamos con las imágenes y comenzábamos a comprender el sentido de las mismas, y a vislumbrar entre esas tomas aparentemente anodinas y superficiales un verdadero universo repleto de información, presentado con una sinceridad en su puesta en escena que no podría haber sido recreada por cineastas profesionales y una perspectiva altamente singular. Es cierto que ese mundo recogido por las cámaras se mostraba esquivo -tan solo los niños se mostraban francos ante la cámara-, pero entendimos que esa era su verdadera naturaleza; nos quedó claro que para ver y comprender al "otro" teníamos que reformular primero nuestro "yo" (Clifford \& Marcus, 1986).

La perspectiva de esa visión, en este caso, resultó esencialmente qom. Confirmamos la idea de que la descripción (ekphrasis) es siempre cultural (Ramos, 2004); y que habiendo grabado ellos, algo importante teníamos ganado. Es cierto que vieron a través de ojos tecnológicos, pero al fin y al cabo fueron sus ojos y sus manos. Podemos llamar analfabeta esta visión y construcción de la realidad, o sencillamente un habla en el sentido saussureiano, marcada por una escritura torpe, sin sintaxis ni corrección, presa del automatismo y la improvisación.

De ahí, que surjan propuestas de cinealfabetización (Tudurí, 2010), porque la palabra hablada puede ser registrada en forma de historias orales, o las crónicas y diarios personales pueden ser escritos con un mínimo de destreza; sin embargo, el audiovisual presenta una barrera infranqueable que ya no está en la cámara con la que se puede escribir torpemente, sino en el montaje y la sonorización donde se precisa el dominio, al menos básico, de programas complejos de edición.

Es cierto que el contrato que se establece entre investigador y población, o entre fotógrafo y modelo, puede caer en un destino faustiano desde el momento en que la tecnología y lenguajes proporcionados vayan en detrimento de recuperar o preservar las culturas y valores originales (Ginsburg, 1991, p 96). 
Pero también es cierto que el futuro es el presente, las nuevas tecnologías ya están aquí y alcanzan cada confín del mundo. La prueba son las innumerables páginas web suscritas y creadas por la comunidad qom para reivindicar sus derechos y exponer su lucha política, o el inabarcable material audiovisual colgado en diferentes páginas con entrevistas, actos públicos, fotografías, manifiestos, etc.

Es cierto que la cultura que viene a denominarse occidental, blanca, de clase media, puede aniquilar con su aparato tecnológico cualquier ápice remanente de la autenticidad de las culturas aborígenes, pero más cierto es que son esas culturas las que tienen que decidir por sí mismas qué camino seguir frente a la presencia de esas tecnologías. El coste de esa asimilación no tiene por qué implicar la pérdida del bagaje cultural, la experiencia de lo que nos ha ocurrido a nosotros mismos, puede serles de gran ayuda.

Los proyectos de producción audiovisual compartida deben desarrollarse a nuestro juicio tomando en consideración una triple entente: la labor científica de los expertos (antropólogos, médicos, arquitectos, urbanistas, etcétera); los cineastas, especialistas en el lenguaje y las técnicas audiovisuales y las poblaciones involucradas; sin perder de vista, desde luego, a los patrocinadores y los espectadores.

Decidir la estructura narrativa que debería llevar la obra y el posible guión literario fueron los siguientes pasos de responsabilidad del equipo. Ante las veintidós horas de material bruto perteneciente a zonas geográficas, personas y miradas de estilo diferentes, había que tomar una decisión formal y de estilo, sin olvidar que el valor comunicativo de la obra debía quedar por encima del archivístico, testimonial o científico.

La película resultante quedó de esta forma dividida en bloques temáticos correspondientes a las actividades más sobresalientes y recurrentes: ganadera y agrícola, vida familiar, juegos, religión, política asamblearia, bailes y entrevistas. Y cada uno de estos apartados quedaba precedido de un rótulo introductorio, cuyo texto fue tomado de un libro de testimonios históricos (Sánchez, 2009), en consonancia con el contenido de cada capítulo. Por último, el conjunto de la obra quedó precedido de una breve introducción en off, grabada por una de las participantes qom, que revela al espectador el contexto geográfico y etnográfico en el que tienen lugar los acontecimientos, mientras el resto se desenvuelve sin intervención de narrador externo.

El montaje ha procurado respetar el tempo de grabación y la mirada de sus autores, manteniendo planos secuencia de larga duración y dando prioridad al sentir del cameraman ante el objeto por encima de los errores técnicos. Se ha optado, pues, por seleccionar los planos de acuerdo con su valor documental, emotivo y testimonial, descartándose los fragmentos repetitivos y los errores graves de imagen y sonido. Por último, la sonorización ha tratado de conseguir unas mezclas lo más respetuosas posible con los originales, eliminando las distorsiones, roturas y fragmentos imperceptibles.

Es importante señalar que tanto el guión como la estructura narrativa de la obra fueron 
mostrados a los representantes de la comunidad y a la dirección científica del proyecto para su supervisión y comentarios.

Uno de los ejes centrales sobre el que discurre este tipo de obras transfronterizas es lo que viene a denominarse dentro de los estudios de antropología visual la transculturalidad o multiculturalidad, y que los autores sitúan en un periodo histórico denominado poscolonialismo. Asimismo, estas relaciones de interdependencia entre países y economías están presentes en todo momento en el trabajo profesional de cada uno de los integrantes y en las obras resultantes, obligando a adoptar una posición ética e ideológica en cada una de las etapas del proceso de cooperación (Cuevas \& Benítez, 2011).

La relación del autor occidental, ya venga del campo de las ciencias o de las humanidades con las materias y comunidades de intervención en los países en vías de desarrollo ha recorrido diversas etapas a lo largo de la historia. Y estos periodos han estado marcados por las relaciones de interdependencia establecidas entre unos pueblos y otros, relaciones de producción que han condicionado recíprocamente la representación colectiva que tienen unos de otros.

En el terreno del documental y de la antropología visual nos enfrentamos a un dilema que toma como base esta relación centenaria del hombre blanco con los pueblos indígenas. Los modelos de actuación puestos en práctica por los movimientos progresistas en la Europa de los sesenta y que se toman como referencia aún hoy día, parecen tambalearse. Los intentos de Jean Rouch en África por construir obras documentales vistas desde el otro lado, con plena consciencia del lugar ocupado por el autor en la estructura colonizadora, y apoyado por equipos técnicos que lo hacían posible, reciben hoy día críticas más que justificadas, precisamente desde ese otro lado, dignas de tener en cuenta.

Si en los años sesenta, Rouch representa este tipo de esfuerzo, al parecer frustrado (Arensburg, 2010, p. 20) ${ }^{2}$, por crear una visión crítica, o más bien autocrítica, de la construcción de obras fílmicas de los pueblos colonizados ¿qué posibilidades tenemos hoy día si aceptamos que nuestro campo de actuación cae dentro de los márgenes impuestos por la cooperación internacional, y si entendemos ésta como una prolongación de la fase de dominio de unos países respecto de otros? Los prejuicios hacia otras culturas parecen seguir tan vivos y presentes como entonces.

Nos jactamos de hablar de época postcolonial, de transculturalidad y multiculturalidad, cuando en realidad seguimos debatiéndonos entre dos líneas de actuación: una mirada sincera y respetuosa, y otra llena de prejuicio y engaño. Continuamos hablando de "Non- Western Art", de "música étnica", "arte primitivo", "otras tendencias", "arte salvaje" impotentes para conocer realmente y valorar otras culturas, cegados por un recalcitrante egocentrismo (Elkins, 2003, p. 118). Seguimos

2 Utilizando la expresión de Ibrahima Signaté en la obra citada. 
sorprendiéndonos del increíble bagaje cultural de otros pueblos no-occidentales, encasillando a todos ellos con etiquetas globalizadoras, absortos y complacidos en una cultura narcisista y absorbente.

El problema ético que aparece en el trabajo antropológico, y más específicamente y con mayor vehemencia en la antropología y la comunicación audiovisual, trasciende los principios de responsabilidad profesional para adentrarse en un problema de método y de tratamiento, para reconocer en qué medida pueden elaborarse obras conjuntas realmente paritarias. Los principios de ética profesional (Heider, 1976) suponen un punto de partida inexcusable para todo proyecto audiovisual, pero la cuestión, a nuestro parecer, máxime cuando se trata de proyectos de autoría compartida, es encontrar fórmulas de cooperación que sean conscientes de la posición de poder que adopta cada una de las partes (Pink, 2004, p. 37).

El esquema seguido por los estudios antropológicos o de producción audiovisual en los pueblos colonizados debe superar tanto el modelo unidireccional, positivista, de disección científica de su objeto de estudio sin la participación de los sujetos investigados, como el modelo pretendidamente no liderado y carente de toda directriz, pero que a la postre no es más que el resultado de una aproximación ingenua, acomplejada, o un puro ejercicio de poder soterrado, que acaba por no convencer a nadie. Partamos pues de las condiciones reales en las que se sustentan los proyectos, teniendo presente las imposiciones que a nivel internacional, nacional y profesional se imponen manifiesta o latentemente, y desde ahí, trabajemos juntos en beneficio de todos: de las comunidades y de los investigadores.

\section{CONCLUSIONES}

En el proyecto "Ser Qom", como en otros muchos, lo singular es que los informantes han elegido el material que han querido grabar, e incluso las palabras y la narración con que han querido que sean presentadas sus vidas, relegando el papel de los realizadores a propuestas narrativas, de montaje y de sonorización, convenientemente discutidas y aceptadas entre todos. En la práctica, los realizadores han completado un trabajo documental de archivo (footage production o research footage) en una obra que ha reducido considerablemente la distancia entre equipo técnico y población. Siendo conscientes de las distancias entre las culturas de los agentes involucrados, se ha optado por la realización de una obra interactiva (Del Río \& Álvarez, 1999, p. 133-34), que fuera capaz de establecer un diálogo entre las culturas qom, científica y del espectador.

\section{REFERENCIAS}

Arensburg, G. (2010). Cinematografías de África. Un encuentro con sus protagonistas. Las Palmas de Gran Canaria: Casa de África.

Barnes, D. B., Taylor-Brown, S., \& Wiener, L. (1997). I Didn't Leave Y'all on Purpose: HIV-Infected Mother's Videntaned I egacies for Their Children. Oualitatize Sociolnow. 20 
(1):7- 31 .

Briski, Zana \& Kauffman, Ross (2007). Los niños del barrio (Born into brothels: Calcutta's red light kids).[Cinta cinematográfica]. Estados Unidos de América: Karma Films.

Camas, V., Martínez, A., Muñoz, R. \& Ortiz, M. (2004). Revealing the Hidden. Making Antrophological Documentaries. En Working Images. Visual Research and Representation in Ethnography. Londres: Routledge.

Cardin, L. (2010). Comunidad Qom La Primavera. Recuperado el 6 de julio de 2011, de http:/ / vimeo.com/user6341563.

Carelli, V. (1986-2011): Vídeo Nas Aldeias. (Proyecto con varios documentales) Equipe VNA, Olinda.

Clifford, J. \& Marcus, G. E. (1986). Writing Culture: The Poetics and Politics of Ethnography. Berkeley: University of California Press.

Collier, J., \& Collier, M. (1990). Visual Anthropology. Photography as a Research Method. Alburquerque: University of New Mexico Press.

Cuevas, J., \& Benítez, A. J. (2011). Los límites a la información en la producción audiovisual en el marco de la cooperación para el desarrollo. Trabajo presentado en Actas del III Encuentro Internacional de Investigadores en Información y Comunicación. Servicio de Publicaciones de la Universidad Complutense de Madrid.

De qué. (2010a). [Cinta cinematográfica]. España: CSA.

Del Río, P., \& Álvarez, A. (1999). La puesta en escena de la realidad cultural. Una aproximación histórica cultural al problema de la etnografía audiovisual. Revista de Antropología Social, 8: 121-136.

Elkins, J. (2003). Visual Studies. A Skeptical Introduction. Londres: Routledge.

Flaherty, R.J. (1922). Nanook of the North. [Cinta cinematográfica]. EEUU: Phate Pictures,

Flores, C. (2005). Qa Loq Laj Iyaaj. [Cinta cinematográfica]. México: Universidad de Ciencias y Artes de Chiapas.

Flores, C. (2005). Video indígena y antropología compartida: una experiencia colaborativa con videoastas maya-q'eqchi' de Guatemala. Liminar, Estudios Sociales y Humanísiticos.

Ginsburg, F. (1991). Indigenous Media: Faustian Contract or Global Village? Cultural 
Anthropology, 6 (1): 92-112.

Heider, K. G. (1976). Ethnographic Film. Texas: University of Texas Press.

INARRA. (2011). Imagens, Narrativas e Praticas Culturais. [Cinta cinematográfica]. Recuperado el 6 de julio de 2011, de www.youtube.com/watch?v=IGy8q2MFzf0.

Mlv, C. (2011). Pensamiento no premeditado. Proyecto uno. [Cinta cinematográfica]. España: Asociación Civil Qom

Pink, S., Kürti, L. \& Afonso, A. I. (2004). Working Images. Visual Research and Representation in Ethnography. Londres: Routledge.

Pink, S. (2004). Doing Visual Ethnography. Londres: Images, Media and Representation in Research. Sage.

Ramos, M. J. (2004). Drawing the lines. En Working Images. Visual Research and Representation in Ethnography. Londres: Routledge.

Ruby, J. (1991). Speaking For, Speaking About, Speaking With, or Speaking Alongside. An Anthropological and Documentary Dilemma. Visual Anthropology Review, 7(2): 5067.

Ruby, J. (2011). On the Necessity of Being Painfully Obvious or the (Mis)Appropiattion of the Ethnographic. Recuperado el 6 de julio de 2011, de www.anthro.umontreal.ca/personnel/beaudetf/pdf

Samprón, A. (2011). El uso de la "antropología compartida" Una investigación con jóvenes indígenas urbanos. Recuperado el 2 de julio de 2011, de www.sistemasmart.com.br

Sánchez, O. (2009). Historias de los aborígenes tobas del Gran Chaco contadas por sus ancianos. Madrid: Librería de la Paz.

Sarmiento, T. E. (2005). Nam Qom. Una comunidad al margen. [Cinta cinematográfica]. España: Universidad de Granada.

Sinfonía Tetuán. (2010b). [Cinta cinematográfica].España: CSA.

Tamagno, L. \& Maidana, C. (2007). Ntaunaq Nam Qom. Identidad y lucha por la tierra. Gente toba en la ciudad. [Cinta cinematográfica]. España

Tamagno, L. \& Maidana, C. (2007). No todo tiene que quedar escrito. Recuperado el 6 de julio de 2011, de www.sistemasmart.com.br/ram/arquivos/.pdf .

Tudurí, G. (2010). Manifiesto del cine sin autor. Recuperado el 30 de julio de 2011, de

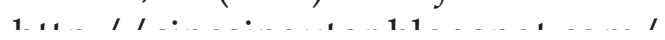


Turner, T. (1990). The Kapayo Video Project: a Progress Report. Revue de la Commission d'Anthropologie Visuelle. Recuperado el 2 de julio de 2011, de http:/ / www.anthro.umontreal.ca

Wang, C., Burris, M.A. \& Yue Ping, X. (1996). Chinese Village Women as Visual Anthropologist: A Participatory Approach to Reaching Policymakers. Soc. Sci. Med. 42 (10): 1391-1400.

Worth, S. \& Adair, J. (1997). Through Navajo Eyes: An exploration in film communication and anthropology. Alburquerque: University of New Mexico Press.

\section{José Cuevas}

Doctor en Ciencias de la Información por la Universidad Complutense y Licenciado en Ciencias de la Educación por la Universidad de Sevilla. Fotógrafo y realizador especializado en el campo del documental y de la televisión educativa. Autor de numerosas obras documentales de carácter social e histórico, y de series de televisión. Ha publicado libros e impartido talleres dedicados a la fotografía como herramienta para la adquisición de conocimiento desde una perspectiva filosófica. En la actualidad comparte su labor profesional con la de profesor asociado en las universidades Complutense y Carlos III, ambas de Madrid.

\section{Amelia Álvarez}

Doctora en Psicología por la Universidad Autónoma de Madrid. Actualmente, tras su paso por la Universidad de Salamanca (1994-2006), es profesora en la Universidad Carlos III de Madrid, donde desempeña su labor investigadora como miembro del Laboratorio de Investigación Cultural. Actualmente está participando en diversos proyectos en América Latina. Es fundadora de la revista Infancia y Aprendizaje, que codirigió con Pablo del Río desde 1978 hasta 1996, y fundadora de la revista Cultura y Educación, que ha dirigido desde 1996 hasta 2008. Es miembro del consejo editorial de la revista Mind, Culture and Activity.

\section{Anto J. Benítez}

Licenciado en Ciencias de la Información (1989) y Doctor en Comunicación Audiovisual (2006) por la Universidad Complutense de Madrid. Realizador por oposición en Telemadrid (1990-2007), en situación de excedencia. Actualmente es profesor de Teoría y Técnica de la Realización y Tecnologías y Técnicas del Audiovisual en el Departamento de Periodismo y Comunicación Audiovisual de la Facultad de Humanidades, Comunicación y Documentación; Universidad Carlos III de Madrid. Una de sus líneas de investigación abarca realización en medios audiovisuales y cooperación. 